\title{
Effects of Alcohol Advertisements and Alcohol Consumption amongst Adolescents in Selected High Schools in the Eastern Cape, South Africa
}

\author{
Lungisani Moyo \\ Department of Communication, University of Fort Hare, Private Bag X 1314, Alice 5700 \\ Email:lungie06@gmail.com
}

\author{
Doi:10.5901/mjss.2014.v5n23p1649
}

\begin{abstract}
Alcohol consumption among adolescents in South Africa remains on the rise, especially among high school learners. The study explored the effects of alcohol advertisements and alcohol consumption amongst adolescents focusing on selected high Schools in the Eastern Cape Province, South Africa. Results of this study revealed that most adolescence who end up consuming alcohol have been mostly exposed to alcohol advertisements that appeals to them the most and lures them to drinking. However there are other contributing factors such as, the influence of friends, peer pressure and family problems that cannot be brushed aside. It was also revealed in this study that alcohol advertising makes adolescence aware of different brands. This information ultimately makes students feel connected to alcohol advertising, thereby leading them to consuming alcohol.
\end{abstract}

Keywords: alcohol, adolescent, advertising, high school

\section{Introduction}

Alcohol is prominent among the many branded consumer goods that young people, in particular, increasingly use as a way of signalling their identity and place in the world they further view alcohol as a form of recreation and drink it with the deliberate intention of becoming intoxicated (Shand, Gates, Fawcett \& Mattick, 2003). Advertising is never static, even in established markets, as new cohorts of young people become available as targets for marketing activity on a continual basis as they mature. Market segmentation and targeting is used by the alcohol industry to ensure that significant amounts of advertising are placed where youth are more likely to be exposed to it than adults. Paid placements of products in films, television, books, and video games is another way to embed alcoholic beverages in the daily lives of young people (Caswell \& Maxwell, 2005).

Drinking is portrayed as normal behaviour with no adverse effects and consequences by advertisers (Strasburger, 2001). Most techniques used by media in the advertising of alcohol such as sexual imagery and celebrity endorsements are argued to be appealing to the youth (Grube, 2004). Alcohol consumption is normalised by promoting positive expectancies such as consumption with attractive symbols, role models and outcomes, (Austin \& Hust, 2005; Chen, Grube, Bersamin, Waiters \& Keefe 2005). Alcohol advertising is among the most heavily advertised products worldwide (Endicott, 2005) resulting in increasing exposure to underage youth (Centre on Alcohol Marketing and Youth, 2003).

Endicott (2005) notes that marketing of alcohol to young people is crafted to mirror, express dominant representation of youth culture and lifestyles. The alcohol industry uses market segmentation to ensure that significant amounts of advertising are placed where youth are more likely to be exposed to it than adults (Caswell \& Maxwell, 2005).

Shand, Gates, Mattick and Fawcett, (2003) contend that alcohol is a form of recreation and drink with the deliberate intention of becoming intoxicated by youth. Coleman and Cater, (2005) further suggests that young people do not classify themselves as binge drinkers, despite being identified as such according to regular, weekly consumption levels.

This study therefore seeks to look at the impacts of alcohol advertising and consumption on adolescents and assess how this develop or further obscure their lives. This study is important since adolescents form a fundamental part of any nation's populace and the base of tomorrow's work force. This becomes important because of the report of high rate of alcohol consumption by adolescents in South Africa, especially those in High school (Flisher \& Chalton, 1995). The research seeks to make a sound contribution towards productive arguments in justifying how alcohol advertising leads to consumption by adolescents. Mass communication theories recognize advertising as a tool that makes consumers aware of many products (O'Guinn, 2005). This research seeks to evaluate among other things why adolescence consume 
alcohol and come up with practical recommendations towards solving the arguments associated with existing alcohol advertisements and alcohol consumption by adolescents.

\section{Literature Review}

Attention to and liking of alcohol advertising is strongly related to positive views on drinking, increased intentions to drink as an adult and increased drinking behaviour among youth (Agostinelli \&Grube, 2002). Calfee \&Scheraga, 1994; Stacy et al., 2004; Chen et al, 2005; Ellickson et al, 2005, Collins et al, 2007; Fisher et al., 2007 also found out that there is a close link between alcohol advertising coverage and drinking on adolescence that is, the effects of media on the behaviour and lifestyles of adolescence. Ellickson, Collins, Hambarsoomians, \& McCaffrey, 2005; Hanewinkel \& Sargent, 2007; Henriksen, Feighery, Schleicher, \& Fortmann, 2008; McClure, Dal Cin, Gibson, \& Sargent, 2006; Sargent, Wills, Stoolmiller, Gibson, \& Gibbons, 2006 argue that alcohol advertising has the power to influence adolescents' drinking behaviours and that there is a positive effect between exposure to alcohol advertising and the initiation or reinforcement of alcohol consumption.

All this is achieved through direct targeting of a particular age group within a particular society, thereby having a direct impact on the economy, society, the national and international policies of a wide range of actors, including Governments, International Organizations, Business, Labour and Civil Society (Martin et al., 2002). Endicott, (2005) also substantiated that alcohol is among the most profoundly advertised products worldwide resulting in increasing exposure to underage youth.

Empirical proof points out to high exposure levels of alcohol advertising containing attractive elements to children and underage youth. These vulnerable audiences are openly targeted marketers thereby increasing the likelihood of many such elements contained in alcohol advertisements by children and youth (Chung et al., 2010; Fielder, Donovan; Ouschan, 2009; Ringel, Collins; Ellickson, 2006; Winter, Donovan; Fielder, 2008).

The United States requires that more than $50 \%$ of the exposed audience be over 21, however, beer advertisers have no restrictions on the use of sports celebrities. Centre on Alcohol Marketing and Youth (2002) found that in 2001, advertisers delivered $45 \%$ more beer advertising to youth than to adults in magazines when they examined the exposure of the youth to alcohol advertising in magazines, on television and on radio in New York.

World Health Organization, (2007) substantiated that alcohol consumption and its related harms are a serious public health issue for many countries. Babor et al., 2003 also distinguished that young people are particularly vulnerable to alcohol related harms and risk of disease and injury, and social consequences relates to both the volume of consumption and pattern of alcohol use.

\subsection{Theoretical Framework}

This study builds on three theories, the Cognitive Dissonance theory, Theory of Planned Behaviour/ Reasoned Action and the Uses and Gratification theory.

\subsubsection{Cognitive Dissonance theory}

Leon Festinger (1957) synthesized a set of studies to distil a theory about communication's social influences. Cognitive dissonance enjoyed great popularity from the late 1950s through the mid-1970s. Theoretical problems and conflicting findings lead to temporary replacement by similar "self" theories in the early 1980s, but cognitive dissonance regained its place as the umbrella theory for selective exposure to communication by the late 1980s.

Cognitive dissonance is a communication theory adopted from social psychology. The title gives the concept: cognitive is thinking or the mind; and dissonance is inconsistency or conflict. Cognitive dissonance is the psychological conflict from holding two or more incompatible beliefs simultaneously. Cognitive dissonance is a relatively straightforward social psychology theory that has enjoyed wide acceptance in a variety of disciplines including communication. The theory replaces previous conditioning or reinforcement theories by viewing individuals as more purposeful decision makers; who strive for balance in their beliefs. The theory suggests that, dissonance is psychologically uncomfortable enough to motivate people to achieve consonance, and in a state of dissonance, people will avoid information and situations that might increase the dissonance. How dissonance arises is easy to imagine, it may be unavoidable in an information rich-society. How people deal with their dissonance is more difficult and different. The Dissonance theory applies to all situations involving attitude formation and change. This theory is able to manipulate people's minds into 
certain behaviour, by doing so these people will alter their attitudes themselves. It is especially relevant to decisionmaking and problem-solving.

\subsubsection{Linking Cognitive Dissonance theory to the study}

Relating the Cognitive Dissonance theory to this study, in simple terms, students who If presented with decisions or information that creates dissonance, they are able to use dissonance-reduction strategies to regain equilibrium, especially if the dissonance affects their self-esteem. That is if students are exposed to different kinds of alcohol advertisements they are able to make their decisions to either consume alcohol or not depending on their self-esteem and the influence that the advertisement have on them. This case can be different when it comes to those students who are loyal to their products. That is for example, if a student is inclined to Castle lite, then sees an advertisement of Hansa, that person is not going to have dissonance simply because he/she is loyal to that product. The same can be said to those who prefer certain products, that is, for example to a student who prefers coke over beer, there will be no dissonance over choice of product since the person has a preferred product.

\subsubsection{Theory of Planned Behaviour/ Reasoned Action}

The theory of reasoned action (TRA) was formulated by Ajzen and Fishbein in 1980. The theory resulted from attitude research from the Expectancy Value Models. Ajzen and Fishbein formulated the TRA after trying to estimate the discrepancy between attitude and behaviour. This TRA was related to voluntary behaviour. Later on behaviour appeared not to be $100 \%$ voluntary and under control, this resulted in the addition of perceived behavioural control. With this addition the theory was called the theory of planned behaviour $(T p B)$. The theory of planned behaviour is a theory which predicts deliberate behaviour, because behaviour can be deliberative and planned.

Theory of Reasoned Action suggests that a person's behaviour is determined by his/her intention to perform the behaviour and that this intention is in turn, a function of his/her attitude toward the behaviour and his/her subjective norm. The best predictor of behaviour is intention. Intention is the cognitive representation of a person's readiness to perform a given behaviour, and it is considered to be the immediate antecedent of behaviour. This intention is determined by three things: their attitude toward the specific behaviour, their subjective norms and their perceived behavioural control.

The theory of planned behaviour holds that only specific attitudes toward the behaviour in question can be expected to predict that behaviour. In addition to measuring attitudes toward the behaviour, we also need to measure people's subjective norms, their beliefs about how people they care about will view the behaviour in question. To predict someone's intentions or knowing their beliefs can be as important as knowing the person's attitudes.

Finally, perceived behavioural control influences intentions. Perceived behavioural control refers to people's perceptions of their ability to perform a given behaviour. These predictors lead to intention. A general rule is that the more favourable the attitude and the subjective norm, and the greater the perceived control, the stronger should be the person's intention to perform the behaviour in question. The theory provides useful information for the development of communication strategies. This theory is also used in evaluation studies. Other usages of the model include: voting behaviour, disease prevention behaviour, birth control behaviour and consumption prediction (Jaccard \& Davidson, 1972)

\subsubsection{Linking Theory of Planned Behaviour/ Reasoned Action to the study}

If students are exposed to different alcohol advertisements, the fact that they make or decide to drink after viewing the advert does not specifically apply since the theory of planned behaviour is a theory which predicts deliberate behaviour, because behaviour can be deliberative and planned.

\subsubsection{Uses and Gratification theory}

The Uses and gratification theory suggests that media users play an active role in choosing and using the media.

Users take an active part in the communication process and are goal oriented in their media use (Blumler \& Katz 1974). These theorists articulate that media users seek out a media source that best fulfils their needs. Uses and gratifications assume that the users have alternate choices to satisfy their needs. Uses and gratifications theory takes a more humanistic approach to looking at media use. Blumler \& Katz (1974) believe that there is not merely one way that the populace uses media. Instead, they believe there are as many reasons for using the media, as there are media users. 
According to the theory, media consumers have a free will to decide how they will use the media and how it will affect them. Blumler \& Katz's values are clearly seen by the fact that they believe that media consumers can choose the influence media has on them. Uses and gratification is the optimist's view of the media. The theory takes out the possibility that the media can have an unconscious influence over people's lives and how they view the world. The idea that citizens simply use the media to satisfy a given need does not seem to fully recognize the power of the media in today's society. In view of the three theories, this study will adopt the uses and gratification theory as an analytical tool mainly because it is the one that is more applicable to the problem at hand.

\subsubsection{Linking Uses and Gratification theory to the study}

Uses and gratification theory can be seen in cases such as alcohol advertisement selection. People select advertisements not only to fit a particular mood but also in attempts to show empowerment or other socially conscience motives. There are many different types of advertisements and consumers choose from them to fulfil a particular need. That is those students who may say after watching a certain alcohol advertisement they feel like drinking chooses to be influenced on their own way.

\subsection{Alcohol Advertising in South Africa}

Parry, (1998) argued that, prior to the colonial era; alcohol consumption in South Africa was restricted to cultural and religious use by the indigenous black people. The Dutch and British colonists introduced social drinking to the country and later used alcohol as a means of payment for poor farm labourers. Eventually, alcohol was used as a method for controlling certain parts of the population. The topic of alcoholism was considered a dark secret during apartheid and only in the past years has it begun to receive the attention it deserves on a national government level. One of the first instances of alcohol being used for non-communal or non- ceremonial purposes was by the Dutch when attempting to convert the local people to Christianity (Parry, 1998). Naturally, this created a heavy dependency on alcohol in rural, agricultural areas and by the end of the 19th century; alcohol had become so serious a societal problem that the British colonial government prohibited drinking by blacks because they believed it caused social decay and disorder among this group (Parry, 1998).

In 1969, the advertising industry in South Africa assumed the moral and financial responsibility for monitoring itself. The industry voluntarily formed Advertising Standard Authority (ASA) and adopted a code of conduct based on the British Code of Advertising Practice, (hereafter referred to as the Code) and on the International Code of Advertising Code, prepared by the International Chamber of Commerce. The purpose of this Code was to ensure that certain standards of fair dealing and honest dealing were met as well as setting out certain criteria for professional conduct for those involved in the industry. In addition the Code was a source of reference to the public as it sets out clearly the ethics and limitations accepted by those working in and using advertising (Woker, 1999).

Parry, (1998), further argued that, in the early $20^{\text {th }}$ century, the government used alcohol as a means of social control. By law, blacks were only allowed to drink in 'African' beer halls, and were strictly prohibited from drinking in bars or other public areas. In 1909 in Natal, the Native Beer Act was passed which stipulated that legal consumption of traditional African beer was allowed only within the municipal beer halls in Durban. This became the model for alcohol legislation throughout South Africa during the early 1900s. In addition to close regulation consumption, the government ensured that alcohol was more freely available for sale to Indians and 'Coloureds', but not to Africans. Due to the restrictions placed on them, brewing and consuming alcohol became an act of defiance for Africans under apartheid and led to the creation of shebeens (Parry, 1998).

\section{Policy Formation on Alcohol Advertising in South Africa}

Prior to 1994, the vast majority of alcohol policy formation was made solely by the state. The decision making process was highly fragmented with various government parties making their own policies and applying them only in their direct sphere of influence. Since the end of apartheid, alcohol policy formation was influenced by a greater number of players, making use of parliamentary portfolio committees (Consumption of alcohol by children, Section 150, Licensing Act 2003).

As is the case in most nations, current alcohol policy is being influenced by organizations with a vested interest in the industry, such as South African Breweries (the world's second largest brewer by volume). The alcohol industry influences policy-formation through both direct engagements with policy makers, as well as indirectly through the Industry Association for Responsible Alcohol Use. This organization is funded entirely by the major producers of alcohol in South 
Africa and was established to "coordinate and direct the liquor industry's efforts to reduce and prevent the abuse of its products (Government Gazette No.18135.1997). The alcohol industry has a large degree of influence over policy formation and the prevalence of advertising in the townships demonstrates that little has been done to curtail the efforts of the alcohol industry to exploit the part of the population that can least afford to buy alcohol and which has the highest rate of alcoholism. In October of 1997, the Department of Health hosted a workshop to look into the need for greater restrictions on alcohol advertising, promoting counter-advertising and health promotions on alcohol use but could not come up with solid decisions that could lead to the amendment of the existing policy on with alcohol advertising.

\section{Alcohol Policy Initiatives in South Africa- prior to 1994}

The majority of alcohol legislation prior to 1994 was focused on controlling the sale of alcohol, limiting its consumption by Africans and enforcing drunk driving and related laws.

Outside of the Non-governmental organizations (NGOs) arena, there was very little, if any, attention paid to combating the growing problem of alcohol dependence in the country. As a result, funding from the national government for law enforcement was inadequate and the quality of care varied widely by region. In 1980, the first major attempt at developing public policy to address the country's growing alcohol problem was made. The National Plan to Combat Alcohol Abuse and Alcoholism was introduced in March of 1980. However, it suffered from the fact that it was narrow in scope; it did not address 'risky' drinking; and it lacked a feasible implementation plan (Parry, 1998).

An improved version of the 1980 policy was drafted in 1988 under the name 'National Plan to Prevent and Combat Alcohol and Drug Abuse in South Africa'. But while it was drafted in 1988, the government did not address the issue of implementation until 1992. At this time, the Minister of National Health and Population Development convened a colloquium to discuss implementation, but too few major groups and political parties attended. Consequently, the program received inadequate funding and the policy had little of its intended effect.

One piece of useful legislation that was passed in 1992 was the Prevention and Treatment of Drug Dependency Act which created the Drug Advisory Board. The Drug Advisory Board advised the Minister of Welfare on matters pertaining to alcohol and drug abuse. This represented the first time alcohol abuse and dependence was given a voice at the national government level (Parry, 1998).

\section{Alcohol Policy Initiatives in South Africa- post 1994}

During Nelson Mandela's opening address to Parliament in 1994, he particularly singled out alcohol abuse as one of the important 'social pathologies' that the country needed to address.

In 1995, the South African Alliance for the Prevention of Substance Abuse (SAAPSA) was established (Parry, 1998). SAAPSA was defined as a network of government departments, NGOs and CBOs who wished to work together on common projects to address substance abuse (ibid). The alliance was supported by the World Health Organization and other international public health institutions and was a major step towards bringing the extent of the alcohol problem in South Africa to the forefront. In addition to the creation of SAAPSA in 1995, the Department of Welfare produced its second draft of the National Substance Abuse Strategy. It was designed to "prevent and combat substance abuse, through the intervention of all concerned parties in order to improve quality of life and thereby promote peace and development in line with the Reconstruction and Development Programme (RDP).

The National Substance Abuse Strategy outlined four areas of need: prevention, treatment and rehabilitation, information and research and enforcement and control. While the strategy detailed the role of the national government in combating substance abuse, no attention was paid to the role of provincial or local governments and more especially schools. The importance of addressing the country's alcohol problem was significantly increased when health care was adopted as a constitutional right under both the 1993 and 1996 Constitutions.

The 1996 Constitution on National Drug Master Plan, Republic of South Africa, 1999-2004, pg. 110, provides that it is the state's responsibility to take reasonable legislative and other measures within its available resources to achieve progressive realization of the right to health care. Therefore, the Constitution added to the pressure on the state to provide services to help treat and prevent alcohol abuse (www.info.gov.za.). 


\section{Factors Affecting Alcohol Consumption in South Africa}

During the South African colonialist and later apartheid eras, alcohol was used to establish and maintain economic and social control, particularly on the farms, mines and in urban industry in order to support the economies of the times. Employers on wine and other farms in the Cape, and in the emerging diamond and gold mines to the north, used alcohol to attract and retain workers from rural areas. In addition, as part of the "tot" or "dop" system, alcohol was utilized as partial payment for labour. This system gave rise to widespread alcohol abuse and its associated social and health consequences in the areas in which it is practised (London, Sanders \& te Water Naude, 1998). The "tot" or "dop" system is still practiced on a number of wine farms in the Western and Northern Cape Provinces despite having been outlawed. It takes many forms, including the provision of alcohol as partial payment in lieu of wages and to supplement wages (Parry \& Bennetts 1998).

As far as the mining industry is concerned, there are still specific factors on the mines that predispose mineworkers to drink and misuse alcohol. Unsatisfactory work and living conditions mean that miners usually live in single-sex hostels based at the mine sites with one of the only places to socialize often being the liquor outlet. Boredom and peer pressure that are associated with this lifestyle are also contributing factors to drinking among miners (Parry \& Bennetts 1998, Macheke \& Campbell 1998).

A number of interrelated factors appear to have brought about a generally favourable attitude to drinking among people in South Africa. These include decreased controls over the production, sale and consumption of alcohol combined with rapid urbanisation and the traditional exclusion of women from the job market. There seems to be a high level of acceptance of heavy drinking (especially among men) and very little disapproval of it among South Africans in general. Alcohol drinking can be seen as a very popular pastime for people in South Africa. Most alcohol consumption involves malt beers and wines, while other beverages consumed include distilled spirits and home brews (Rocha- Silva, 1989; Rocha-Silva, de Miranda \& Erasmus, 1996). Drinking occurs primarily during meal times, communion services at church, social functions and gatherings, and while viewing sporting events.

The popularity of sports in South Africa in particular seems to encourage sponsorships involving national sports teams, which in turn create a generally favourable attitude towards the alcohol industry (Parry \& Bennetts 1998).

While some cultural factors serve to increase alcohol consumption (and misuse), others, such as religious dictates, are likely to reduce or prohibit the behaviour. Many religious groupings such as evangelical or fundamentalist Christians, while permitting the consumption of alcohol in moderation and on specific occasions, have strong taboos against drunkenness. For Muslims, Mormons, Jehovah's Witnesses, and other religious groups, however, alcohol consumption is strictly non permissible (Parry \& Bennetts 1998).

Poverty and poor education are considered to be additional factors that contribute to the high levels of production, consumption and availability of alcohol in South Africa (Parry \& Bennetts 1998; 1999). The economic activity involved in the sale of alcohol in the informal sector provides "jobs" to many South Africans who would otherwise have no income. Historically, women have sold alcohol to raise money, and this tradition continues today, with most shebeen owners being women. Access to alcohol from the informal sector is virtually unlimited since constraints (such as opening hours and age restrictions) cannot easily be placed on unlicensed establishments. This ready availability of alcohol serves to encourage its use. With respect to the commercial sector, the alcohol and hospitality industries are also a major source of employment and tax revenue providing thousands of jobs that involve the production of alcohol (Parry \& Bennetts 1998; 1999).

\section{Research Methodology}

\subsection{Participants}

A descriptive methodology was adopted; a sample of 40 participants per school was adopted. Three high schools formed the population of the study; responses were collected from grade 10-12 learners making a total of 120 respondents.

\subsection{Instrument}

The instruments that were used for data collection in this study were documents, questionnaires and focus group discussions. Documents such as The National Drug Master Plan (NDMP) and Advertising Standard Authority code (ASA) were analysed. Tellis (1997a) argues that the strength of documents is their stability, exactness and breadth of coverage. Documents do not change unless tampered with and can be referred to again and again. 
The other data collection instrument which was used to collect information from the respondents was the self administered questionnaire. The distribution of the questionnaire was done with the help of the principals and teachers from all the concerned three schools. As defined by Hair, et al., (2008), a questionnaire is a document consisting of a set of questions and scales to gather primary data. The final instrument used was focus group discussions which Naomi, (2009) describes as a form of qualitative research in which a group of people are asked about their perceptions, opinions, beliefs and attitudes towards a product, service, concept, advertisement, idea, or packaging.

Quantitative data from open-ended questionnaires was analysed using the Statistical Package for Social Sciences (SPSS version 12) and presented in the form of tables and graphs generated in Microsoft Word and Excel. Qualitative data from open-ended questionnaires was analysed thematically, by grouping the data into themes and sometimes quoting what was actually written by respondents. The qualitative data was complemented by other qualitative data from focus group discussions held with students. Together the findings from both quantitative and qualitative data were summarized thematically in order to show emerging trends.

\section{Findings and Discussion}

An analysis of whether participants think that alcohol companies intentionally target the youths.

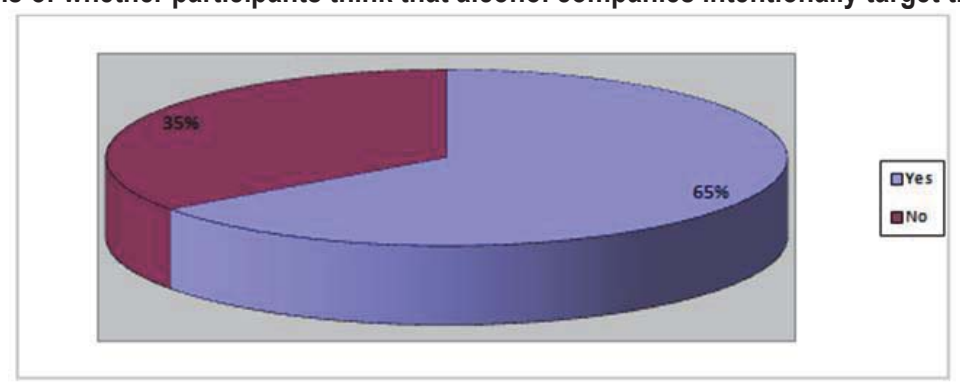

Figure 1: Respondents' view on whether alcohol companies intentionally target the youth when advertising

Respondents were asked their awareness on alcohol companies intentionally targeting them when they use television programmes such as prominent soapies, celebrities and sport matches to promote their products. Most respondents, 78 $(65 \%)$ shared the sentiment that companies do target the youths. This is as most adverts or commercials of alcohol intensified their advertising campaign during prime time viewing. The other respondents $42(35 \%)$ were of the notion that exposure to alcohol advertisements depends on the individual.

Learners saw a link between alcohol companies and the people who design television programmes. They cited that they think alcohol companies do target the youth during certain television programs especially during their favourite soapies such as Rhythm City, Isidingo and Generations and sport games.

\section{Exposure to Alcohol Advertisements}

Respondents were asked whether they were exposed to alcohol advertising, 102(85\%) were exposed as compared to 18 $(15 \%)$ who were not. Evidence from their responses showed that adolescents are exposed to alcohol advertising. This was confirmed in the follow up question, where respondents were asked to identify any brand name (alcohol) and message contained in those advertisements they have seen where names and slogans are not blocked out. This in a way signifies their level of exposure to alcohol advertisements. Even those who were not exposed to alcohol advertising were at least aware of one to two "slogans" for beer. All the focus group discussion participants acknowledged that they are in one way or the other exposed to alcohol advertisements. 


\section{The link between alcohol advertising and drinking behaviour}

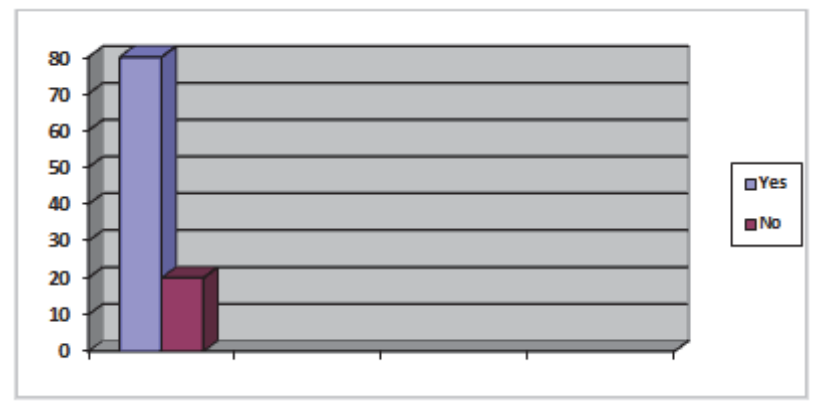

Figure 2: The link between alcohol advertising and drinking behaviour

In general, there was link between alcohol advertising and drinking behaviour, with 96 (80\%) of participants saying 'Yes' to the notion that alcohol advertising leads to drinking behaviour. They cited a number of convincing reasons why they think alcohol advertising leads to drinking behaviour. One of the reasons given by one of the respondents is that,

\section{"Because when you are exposed to something for a long period of time, you finally get convinced that it is the right thing} to do".

This response shows the power of the media. However, the other 24 (20\%) of the respondents said 'No' and that alcohol advertising does not lead to dinking behaviour. Another respondent said that,

".... Drinking is a personal interest and does not need me to see an advert in order for me to start drinking..."

The focus group discussion respondents acknowledged that, indeed there is a link between alcohol advertisements and drinking behaviour. One of the respondents had this to say:

"When you see an alcohol advertisement and the way those who advertise it enjoy, you wish it was you and this will lead us then to go and experiment in order for us to see if we can have the same fun."

\section{Mediums used to Advertisements Alcohol}

Six types of media were examined to find out the forms of media in which respondents were exposed. The dominant forms of media were television (TV), radio, newspaper, magazine, and billboard. Responses indicated that 51(42.5\%) were exposed to alcohol advertisements on television; $6(5 \%)$ of the participants were exposed to alcohol advertisements through radio; 9 (7.5\%) of the total participants were exposed to alcohol advertisements through newspapers; billboards contributed 12(10\%); $4(2.5 \%)$ of the participants indicated that they get their information from the magazines; $38(32.5 \%)$ said that they saw the alcohol advertisements from all the five mediums.

Evidence confirmed that those who are more exposed to alcohol advertisements are the ones consume alcohol after seeing the different advertisements. The majority of participants who watch television are found to be the ones who decide to drink and most of them are from the age group of 18-20 years. The results indicated a relationship between exposure and intension to consume alcohol.

To support the above the following dominant responses were gathered:

"..because when you are exposed to something for a long period of time, you finally get convinced that it is the right
thing to do".
"Drinking is a personal interest and does not need me to see an advert in order for me to start drinking"
"when you see an alcohol advertisement and the way those who advertise it enjoy, you wish it was you and this will lead
us then to go and experiment in order for us to see if we can have the same fun."
"if afforded time and opportunity, I would like to also have that much fun as the people who advertise beer on television".
"anyone has a right to choose and the issue of what is acceptable or not cannot come in place when it comes to alcohol
consumption ....., maybe if it was something like committing a crime then one can say it is not a good thing."
"when you see someone beautiful on television advertising alcohol you will be tempted and want to go and see if there
are any beautiful ladies in taverns...."
"..in as far as I am concerned, I have so far not yet seen a person who is drinking alone. All those people who drink
beer in alcohol advertisements seem to have a lot of friends. So coming to the issue of drinking and having friends, I 
think for me, you need to drink in order for you to have a lot of friends."

"....as for me, I would want to appear on television playing soccer or maybe advertising cars."

"...even if you do not want to be exposed to alcohol, you end up being a victim of it."

"for some of us who follow soccer and are inspired by celebrities, we tend to also follow their live style as we see them as role models. If you look for example, the life styles of the legends like Jabu Pule, who drink as if there is no tomorrow and even admit to the press that he has alcohol problems...even our youth President Julius Malema admitted on national television that he do drink a lot when he was interviewed by Deborah Patta on 3rd degree".

\section{Analysis of Respondents' Consumption of Alcohol}

Since the research was looking at the impact of alcohol advertising and consumption on adolescents, the researcher saw it relevant to look at whether students do consume alcohol or not.

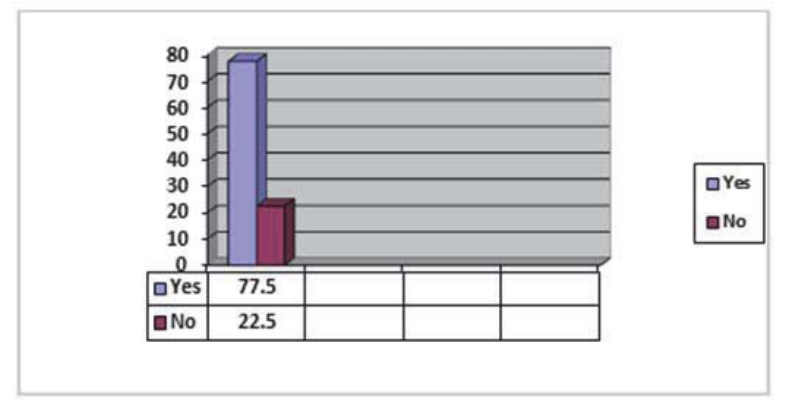

Figure 3: Respondents who consume alcohol

In conducting the research study, it was thought essential to determine if the respondents consume alcohol. The results revealed that, $93(77.5 \%)$ of the respondents do consume alcohol. The other $27(22.5 \%)$ of the respondents indicated that they do not drink alcohol. This was essential so as to determine the type of respondents the researcher was dealing with. This also confirmed the notion of the researcher that adolescents do consume beer and in a way shows that there are many driving forces towards the decision of the youths to consume alcohol. The reasons why some of the adolescents consume beer were shown in the focus group discussions.

During focus group discussions, respondents had more to say than those who completed the questionnaire. They all agreed that they do drink alcohol, although they do not drink on a regular basis. Some of the respondents had this to say:

\footnotetext{
"Yes as students we do drink but the fact is we are not regular drinkers and some of us are not allowed to drink by our parents."

"as adolescents, we just drink for fun and some of us like me are just experimenting, we want to see if what is shown on television is true, that is you can be a champion if for example you drink 'Black label', that is why we do drink"

"... it makes you believe that you will drink alcohol and get to socialize with beautiful women", the other one went on to say "...when you see all those beautiful women in the advertisements, it makes you think that if you drink alcohol you will get beautiful ladies".

"those adolescents who drink beer do so because of peer pressure and they want to look as if they are cool in front of their friends but when they are alone, they regret drinking".
}

\section{Respondent's Thoughts on People Drinking Beer in Television Advertisements and their Association with Lots of Friends}

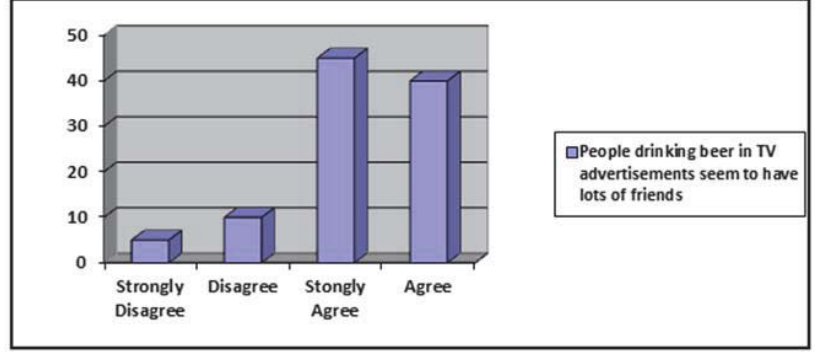

Figure 4: Illustration on whether respondents think people drinking beer in TV advertisements seem to have lots of friends 
Respondents from questionnaire indicated their level of agreement on four-point scales (disagree strongly-agree strongly) whether: "People drinking beer in TV advertisements seem to have lots of friends." 54 (45\%) of the total respondents said they 'strongly agree' that people who advertise beer on television seem to have lots of friends, 48 (40\%) concurred with them, they said they 'agree' to the same notion. The other 6(5\%) 'strongly disagree' and the remaining 12 (10\%) 'disagree'.

Focus group respondents showed more interest in discussing about this issue. They were of the notion that, those people who drink beer in television advertisements seem to have lots of friends. They even came up with interesting examples that the researcher was not expecting from people of their age group. For example one respondent came up with an example of hunters dry. She said,

\section{"... Even the way the guy who advertises hunters dry seem to have a lot of Chinas"}

This affirms to the way he calls his friends.

\section{Conclusion}

The study results also showed that 93 (77.5\%) of the respondents indicated that they do consume alcohol, 27 (22.5\%) of the respondents indicated that they do not drink alcohol. The results indicated adolescents' alcohol consumption, as well as other habits within the social environment which encourage alcohol consumption. The results of the study were consistent with that of literature; Engels \& Knibbe, (2000) who experimenting, problems in human relations, family problems, an alcoholic parent as other the factors that lead to alcohol consumption; Connolly et al., (1994) looked into the subject matter using the associations between age and gender, they no relationship between advertising media with alcohol initiation (after controlling for other factors).

Lorente et al., (2004) purported that it was possible that other factors play a more important role in influencing alcohol initiation among males and younger females than does advertising. Advertising appears to influence the rate and quantity which the young population consumes (Gordon et al., 2010; Anderson et al., 2009).

Shebeens, billboard advertising alcohol were observed to be within 100 meters from the respective schools. There was also a lack of parental guidance and role models from the local communities. The findings of the study are essential to policy makers and education departments as they can ensure that places of alcohol consumption are isolated from education institutions as a control measure to deter youth.

\section{References}

Agostinelli, G., \& Grube J.W, (2002). Alcohol counter Advertising and The Media. Alcohol Research and Health, 26(1), 15-21.

Anderson P, de Bruijn A, Angus A, Gordon R \& Hasting G. (2009). Impact of alcohol advertising and media exposure on adolescent alcohol use: A systematic review of longitudinal studies. Alcohol and Alcoholism, Advance Access published 14 January, 115.

Austin, E.W. \& Hust, S.J.T. (2005). Targeting adolescents? The content and frequency of alcoholic and non-alcoholic beverage ads in magazine and video formats November 1999-April 2000. Journal of Health Communication, 10; 769-785.

Babor TF, Caetano R, Casswell S, Edwards G, Giesbrecht N, Graham K, Grube JW, Gruenewald PJ, Hill L, Holder HD, Homel R, Österberg E, Rehm J, Room R and Rossow I (2003). Alcohol: No Ordinary Commodity. Research and Public Policy. Oxford, Oxford Medical Publication, Oxford University Press.

Blumler J.G. \& Katz, E. (1974). The uses of mass communications: Current perspectives on gratifications research. CA: Sage, Beverly Hills.

Casswell, S. and Maxwell, A. (2005). Regulation of Alcohol Marketing: A Global View Journal of Public Health Policy (2005) 26, 343-358.

Calfee, J.E., and Scheraga, C. (1994). The influence of alcohol advertising on alcohol consumption: A literature review and an econometric analysis of four European nations. International Journal of Advertising 13:287-310.

Centre on Alcohol Marketing \& Youth (CAMY) (2002). Exposure of African-American Youth to Alcohol Advertising. Washington, DC: The Centre on Alcohol Marketing and Youth.

Chen, M., Grube, J.W., Bersamin, M., Waiters, E. \& Keefe, D.B. (2005). Alcohol advertising: What makes it attractive to youth. Journal of Health Communication, 10(6); 553-565.

Chung, Paul, Craig Garfield, Marc Elliott, Joshua Ostroff, Craig Ross, David Jernigan, Katherine Vestal, \& Mark Schuster (2010), "Association between adolescent viewership and alcohol advertising on cable television", American Journal of Public Health Affairs, 100, 555-562.

Coleman L and Cater S (2005). Under age "risky" drinking: Motivations and outcomes. York, Joseph Rowntree Foundation.

Collins, R.L., Ellickson, P.L., McCaffrey, D. and Hambarsoomians .K, (2007). Early Adolescent Exposure to Alcohol Advertising and its Relationship to Underage Drinking. Journal of Adolescent Health, 40, 527-534.

Connolly GM, Casswell S, Zhang JF et al. (1994) Alcohol in the mass media and drinking by adolescents: a longitudinal study. Addiction 89:1255-63.

Consumption of alcohol by children, Section 150, Licensing Act 2003. Available at: http. // www.opsi-gov.uk/ . [Accessed on: June 15, 2010.]

Endicott, R. C. (2005). "Advertising Age's 19th Annual Global Marketing." Advertising Age November 14:1-53. 
Engels, R. C. and Knibbe, R. A. (2000) Young people's alcohol consumption from a European perspective: risks and benefits. European Journal of Clinical Nutrition 54 (Suppl. 1), S52-S55.

Ellickson PL; Collins RL; Hambarsoomians K; McCaffrey DF (2005). Does alcohol advertising promote adolescent drinking? Results from a longitudinal assessment. Addiction 100(2):235-46.

Festinger, L. (1957). A theory of cognitive dissonance. Stanford, CA: Stanford University Press

Fielder, Lynda, Robert Donovan, and Robyn Ouschan (2009), "Exposure of children and adolescents to alcohol television advertising on Australian free-to-air television", Addiction, 104 (7), 1157-1165.

Fisher, L.B., Williams Miles, I., Austin, B. et al. (2007). Predictors of initiation of alcohol use among United States adolescents, findings for a prospective cohort study. Archives of Paediatrics \& Adolescent Medicine, 161(10); 959-966.

Grube, J. W. (2004). Reducing Underage Drinking: A Collective Responsibility. National Research Council (US) and Institute of Medicine (US) Committee on Developing a Strategy to Reduce and Prevent Underage Drinking. Washington (DC): National Academies Press (US).

Gordon R, Hastings G \& Moodie C, (2010) Critical social marketing - the impact of alcohol marketing on youth drinking: qualitative findings. International Journal of Non-profit Voluntary Sect Mark; 15:265-75.

Government Gazette No.18135.1997. 'Liquor Policy Paper and Liquor Bill'. Available

at: www.info.gov.za./bills/ 1997/liquored. [Accessed on: 05 August 5, 2010]

Hair, Jr. J.F., Wolfinbarger, M., Ortinau, D.J. \& Bush, R.P. (2008). Essentials of Marketing Research. New York: McGraw-Hill Companies, Inc. Henderson, Naomi R. (2009). Managing Moderator Stress: Take a Deep Breath. You Can Do This. Marketing Research, Vol. 21 Issue 1, p28-29.

Hanewinkel R, Tanski SE, Sargent JD (2007). Exposure to alcohol use in movies and teen drinking in Germany. International Journal of Epidemiology. 36:1068-1077

Henriksen, L., Feighery, E.C., Schleicher, N., Fortmann, S.P. (2008). Receptivity to alcohol marketing predicts initiation of alcohol use. Journal of Adolescent Health, 42; 28- 35.

Jaccard, J., \& Davidson, A. (1972). Toward an understanding of family planning behaviours: An initial investigation. Journal of Experimental Social Psychology, 2, 228-235.

London L; Sanders D and te Water Naude J (1998). Farm workers in South Africa-the challenge of eradicating alcohol abuse and the legacy of the 'dop' system. South African medical journal = Suid-Afrikaanse tydskrif vir geneeskunde: 88(9):1092-5.

Lorente, F. O., Souville, M., Griffet, J. and Grélot L. (2004) Participation in sports and alcohol consumption among French adolescents. Addictive Behaviors 29, 941- 946.

Macheke and Campbell (1998). Perception of HIVIAIDS on a Johannesburg gold mine. South African Journal of psychology, 28(3)

Martin, S, Snyder LB, Hamilton M, Fleming-Milici F, Slater MD, Stacy A, Chen M-J, Grube JW, (2002). "Alcohol Advertising and Youth", Alcohol Clinical and Experimental Research, 26(6), 900-906.

McClure AC, Dal Cin, Gibson. J and Sargent. J.D (2006). Ownership of alcohol-branded merchandise and initiative of teen drinking. American Journal of Preventive Medicine, 30(4). 277-283.

Nelson Mandela inaugural address in parliament (1994) Available: http://www.info.gov.za/view/DownloadFileAction?id=70476 [Accessed on 03 , August, 2010]

O'Guinn, T.C, 2005. Advertising and integrated brand promotion, $4^{\text {th }}$ Ed .Mason, Ohio: South-Western

Parry, Charles DH, (1998). Alcohol Policy and Public Health in South Africa 4, Oxford University Press, Southern Africa.

Parry C, Bennetts A, (1999). Country profile on Alcohol in South Africa. Alcohol and Public Health in 8 Developing countries: 139-160. Geneva, Switzerland: WHO.

Ringel, J.S., Collins, R.L., Ellickson, P.L. (2006). Time trends and demographic differences in youth exposure to alcohol advertising on television. Journal of Adolescent Health, 39; 473-480.

Rocha-Silva L. (1989). Drinking practices, drinking-related attitudes and public impressions of services for alcohol and other drug problems in urban South Africa. Human Sciences Research Council, Pretoria.

Rocha-Silva, L., S. de Miranda and R. Erasmus. 1996. "Alcohol, Tobacco and Other Drug Use Among Black Youth". Pretoria: HSRC Publishers. $148 p$

Sargent, JD, Wills TA, Stoolmiller M, Gibson J, Gibbons FX (2006). Alcohol use in motion pictures and its relation with teen drinking. Journal of Studies on Alcohol. ; 67:54-65.

Shand, F., Gates, J., Fawcett, J. and Mattick, R. (2003). Guidelines for the treatment of alcohol problems. Sydney: National Drug and Alcohol Research Centre.

Stacy AW, Zogg JB, Unger JB et al. (2004) Exposure to televised alcohol ads and subsequent adolescent alcohol use. American Journal of Health Behaviour 28:498-509.

Strasburger VC. (1995) Adolescents and the Media: Medical and Psychological Impact. Thousand Oaks, CA: Sage.

Tellis, W. (1997). Application of a case study methodology: Available at. http://www.nova.edu.ssss./qR/QR3 tellis2. Html [accessed 15 on: June 2010].

The 1996 Constitution on National Drug Master Plan, Republic of South Africa, 1999- 2004, pg. 110. Available at: www.info.gov.za. [Accessed on, August, 2010]

Winter, M.V., Donovan, R.J. \& Fielder, J. (2008). Exposure of children and adolescents to alcohol advertising on television in Australia. Journal of Studies on Alcohol and Drugs; 69(5); 676-683.

Woker, T (1999). Advertising Law in South Africa, Juta, South Africa

World Health Organization (2007) World Health Organization Expert Committee on Problems Related to Alcohol Consumption. Geneva: World Health Organization. 